\title{
HEMATOLOGIA DE JUNDIÁS EM RESPOSTA AO NÍVEL DE PROTEÍNA NA DIETA
}

\author{
Rafael Lazzari ${ }^{1}$ João Radünz Neto ${ }^{2}$ Viviani Corrêta ${ }^{3}$ Suzete Rossato ${ }^{3}$ \\ Cristiano Costenaro Ferreira ${ }^{3}$ Fernando Jonas Sutili ${ }^{4}$ Marta M.M.F. Duarte ${ }^{5}$
}

1 - Zootecnista, Dr. Prof. Adjunto, Laboratório de Piscicultura, Centro de Educação Superior Norte, Universidade Federal de Santa Maria, RS. E-mail: rafaellazzari@yahoo.com.br.

2 - Engenheiro Agrônomo, Dr., Prof. Associado, Departamento de Zootecnia, Laboratório de Piscicultura,

Universidade Federal de Santa Maria, RS. E-mail: jradunzneto@smail.ufsm.br, autor para correspondência. 3 - Alunos de Pós-graduação em Zootecnia, UFSM, RS..

4 - Acadêmico do curso de Medicina Veterinária, UFSM, RS.

5 - Laboratório de Análises Médicas, LABIMED, Universidade Luterana do Brasil (ULBRA) - Santa Maria, RS.

\section{RESUMO}

Neste trabalho avaliou-se a hematologia de machos e fêmeas de jundiá, alimentados com três níveis protéicos: 24, 27 e $30 \%$ PB. Um total de 270 peixes (135 machos e 135 fềmeas - peso inicial médio de $216,38 \pm 26,73 \mathrm{~g}$ ) foram alimentados durante 100 dias em um sistema de recirculação de água contendo 18 tanques (seis tratamentos com três repetições). Após esse período, capturaram-se seis peixes por tratamento para coleta de sangue a fim de se obterem os valores de hematócrito, hemoglobina, eritrócitos, volume corpuscular médio, hemoglobina corpuscular média, concentração de hemoglobina corpuscular média e plaquetas. Os machos apresentaram maiores valores $(\mathrm{P}<0,01)$ de eritrócitos, hematócrito e hemoglobina em relação às fêmeas. As fêmeas apresentaram maior quantidade de plaquetas. $\mathrm{O}$ teor de proteína da dieta influenciou os valores das plaquetas $(\mathrm{P}<0,01)$ e da concentração de hemoglobina corpuscular média $(\mathrm{P}<0,05)$. O volume corpuscular e a hemoglobina corpuscular média não foram afetados pelo nível de proteína nem pelo sexo $(\mathrm{P}>0,05)$. Conclui-se que machos de jundiá apresentam parâmetros hematológicos superiores às fêmeas. A proteína dietária influencia na quantidade de plaquetas e na concentração de hemoglobina corpuscular dos jundiás.

PALAVRAS-CHAVE: fêmeas; hematócrito; hemoglobina; machos; Rhamdia quelen.

\section{ABSTRACT}

\section{HEMATOLOGY OF JUNDIÁ FISH IN RESPONSE TO DIET PROTEIN LEVEL}

In this study, hematology was evaluated in jundiá fish males and females fed with three protein levels: 24, 27 and $30 \%$ CP. A total of 270 fishes (135 males and 135 females - initial weight of $216.38 \pm 26.73 \mathrm{~g}$ ) were fed during 100 days, in a water re-use system containing 18 tanks (six treatments and three replicates). After this period, six fishes by treatment were captured for blood collection, by which the following values were obtained: 
hematocrit, hemoglobin, red blood cells, mean corpuscular volume, mean corpuscular hemoglobin, mean corpuscular hemoglobin concentration and platelets. The males showed higher values $(\mathrm{P}<0.01)$ of red blood cells, hematocit and hemoglobin comparing to the females. The females showed higher platelet values. Platelets and mean corpuscular hemoglobin concentration were affected by dietetic protein level. Corpuscular volume and mean corpuscular hemoglobin were not affected by the diet protein level nor the fish sex $(\mathrm{P}>0.05)$. It can be concluded that jundiá fish males showed higher hematological parameters compared to females. The dietary protein influences in platelets and mean corpuscular hemoglobin concentration of jundiá fish.

KEYWORDS: females; hematocrit; hemoglobin; males; Rhamdia quelen.

\section{INTRODUÇÃO}

A piscicultura é a atividade de produção animal que mais cresce no Brasil. Isto se deve à intensificação dos sistemas de cultivo e à diversidade de espécies utilizadas nas criações. $\mathrm{O}$ jundiá (Rhamdia quelen) é um bagre de hábito alimentar onívoro e com grandes aptidões para a criação comercial. Em sua dieta, é necessária a inclusão de pelo menos uma fonte de origem animal, pois é um peixe bastante exigente quanto à qualidade da proteína (MEYER \& FRACALOSSI, 2004; LAZZARI et al., 2006).

A proteína é o nutriente mais caro e importante da dieta para o crescimento dos peixes, pois ela constitui a maioria dos tecidos. Alguns trabalhos testaram a influência da proteína no crescimento do jundiá nas fases jovens de criação (MEYER \& FRACALOSSI, 2004; SALHI et al., 2004; PIEDRAS et al., 2006).

O sangue reflete várias alterações metabólicas decorrentes de diferentes condições de criação. Pode ser usado para monitorar situações de estresse causadas por poluentes (ROMANI et al., 2003) e também para avaliar o estado de saúde dos animais.

Alterações na dieta e condições de manejo inadequadas também podem afetar as características hematológicas dos peixes (KLINGER et al., 1996). De acordo com alguns estudos, essas características do jundiá são influenciadas pela composição da dieta (CAMARGO et al., 2005), por herbicidas (CRESTANI et al. 2006), pelo estresse no confinamento (BARCELLOS et al., 2004) e por aflatoxinas na dieta (VIEIRA et al., 2006).

Sendo assim, objetivou-se com o presente trabalho avaliar a relação entre a nutrição e a hematologia para jundiás adultos, avaliando-se os parâmetros hematológicos de machos e fềmeas de jundiá alimentados com diferentes níveis de proteína na dieta.

\section{MATERIAL E MÉTODOS}

O trabalho foi conduzido durante 100 dias nas instalações do Laboratório de Piscicultura da Universidade Federal de Santa Maria - RS (altitude $95 \mathrm{~m}$, longitude $29^{\circ} 43^{\prime} \mathrm{S}$, latitude $53^{\circ} 42^{\prime} \mathrm{W}$ ). O experimento foi delineado em um arranjo fatorial três $\mathrm{X}$ dois (três níveis de proteína bruta $-24,27 \mathrm{e}$ $30 \% \mathrm{~PB}$ - e dois sexos), em triplicata.

Utilizou-se como instalação experimental um sistema de recirculação de água, com filtragem biológica e sistema de aeração do tipo "Venturi”, composto por 18 tanques de polipropileno (280L cada), onde se distribuíram 15 peixes/tanque (nove tanques com machos e nove com fêmeas). Utilizaram-se ao todo 270 peixes (135 fêmeas e 135 machos, peso médio inicial $=216,38 \pm 26,73 \mathrm{~g}$ ), que foram submetidos a um período de adaptação ao sistema de sete dias antes do início do experimento. Deste total, 36 peixes foram capturados aleatoriamente para a realização das análises hematológicas.

As dietas experimentais foram formuladas de acordo com LAZZARI et al. (2006), conforme Tabela 1. O alimento foi ofertado uma vez ao dia (9h), sendo que nos primeiros 20 e nos últimos 20 dias de experimento forneceu-se 1,5\% PV/dia. Nos 60 dias intermediários, a oferta foi de $3 \% \mathrm{PV} /$ dia. Esse manejo foi previamente escolhido devido à adaptação dos peixes e ao controle de sobras nos tanques de criação.

Para a fabricação das dietas, os ingredientes foram pesados e misturados através de misturador até completa homogeneização. Posteriormente, a 
mistura foi umedecida, peletizada e levada à estufa de circulação de ar forçado por $24 \mathrm{~h}$ a $53^{\circ} \mathrm{C}$. Após a secagem, a ração foi moída, peneirada e conservada em refrigerador $\left(-4^{\circ} \mathrm{C}\right)$.

Periodicamente, foram aferidos os parâmetros físico-químicos da água do sistema de criação: temperatura, amônia total, nitrito, alcalinidade, $\mathrm{pH}$ e oxigênio dissolvido. A água para as análises foi coletada na entrada do primeiro filtro biológico, antes de cada alimentação. Para medição da temperatura e oxigênio dissolvido utilizou-se um oxímetro digital (YSI-Yellowsprings-EUA). Para as demais análises utilizou-se o kit colorimétrico (Alfakit, Florianópolis, SC). A análise de amônia foi baseada no método Indotest e a alcalinidade, no método de neutralização (volumétrico), ambos descritos no manual da APHA (2005). O nitrito foi analisado pelo método proposto por FRIES (1971) (método da alfa-naftilamina) e o $\mathrm{pH}$, pelo uso de indicador (AWWA, 1970). Realizaram-se também a limpeza dos encanamentos, a sifonagem de resíduos e a renovação diária de água ( $10 \%$ do volume total).

TABELA 1. Formulação e composição das dietas utilizadas no experimento

\begin{tabular}{|c|c|c|c|}
\hline \multirow[b]{2}{*}{ Ingredientes (\%) } & \multicolumn{3}{|c|}{ Nivel de proteina (\%) } \\
\hline & 24 & 27 & 30 \\
\hline Farinha de carne e ossos & 16 & 20 & 24 \\
\hline Farelo de soja & 20 & 22 & 24 \\
\hline Milho moido & 23,99 & 23,99 & 23,99 \\
\hline Farelo de trigo & 19 & 19 & 19 \\
\hline Óleo de soja & 3 & 4 & 5 \\
\hline Sal comum & 1 & 1 & 1 \\
\hline Inerte (areia fina) & 14 & 7 & 0 \\
\hline Fosfato bicálcico & 1 & 1 & 1 \\
\hline Vitaminas e minerais $^{1}$ & 2 & 2 & 2 \\
\hline \multirow{2}{*}{ Antioxidante $(\mathrm{BHT})^{2}$} & 0.01 & 0.01 & 0,01 \\
\hline & \multicolumn{3}{|c|}{ Composição (\%) } \\
\hline Umidade & 4,2 & 5,2 & 4,1 \\
\hline Proteina Bruta & 24,68 & 27,04 & 30,41 \\
\hline Energia Bruta (kcal/kg) & 3664,5 & 3683,4 & 3749,7 \\
\hline Matéria mineral & 11,09 & 11,03 & 12,16 \\
\hline Extrato etéreo & 6,21 & 7,59 & 9,04 \\
\hline Fibra bruta & 3,8 & 4,14 & 4,41 \\
\hline Cálcio & 1,98 & 2,35 & 2,72 \\
\hline Fósforo & 1,25 & 1,52 & 1,67 \\
\hline
\end{tabular}

${ }^{1}$ Composição da mistura vitamínica e mineral (kg de produto/SUPRE MAIS $($ ): Ác.Fólico: 1200mg, Ác. Nicotínico: 24000mg, Ác. Pantotênico: $12000 \mathrm{mg}$, Cobalto: $10 \mathrm{mg}$ Cobre: $3000 \mathrm{mg}$, Cloreto de colina: $108 \mathrm{~g}$, Ferro: 50000mg, Biotina: $48 \mathrm{mg}$, Iodo: 100mg, Manganês: 20000mg, Selênio: 100mg, Vit.A: 1200000UI, Vit. B1 $4800 \mathrm{mg}$, Vit. B2: $4800 \mathrm{mg}$, Vit. B6: $4800 \mathrm{mg}$, Vit. B12: $4800 \mathrm{mcg}$, Vit. C: 48 g, Vit. D3: 200000UI, Vit. E: 12000 mg, Vit. K3: 2400mg, Zinco: $3000 \mathrm{mg}$

${ }^{2}$ Butil-hidróxitolueno;
Ao final do período de alimentação, dois peixes por tanque (seis por tratamento) foram capturados aleatoriamente para coleta de sangue. A retirada desse material foi realizada por punção na veia caudal, com seringas heparinizadas $(3,0 \mathrm{~mL})$. Após a coleta, as amostras foram acondicionadas em tubos contendo EDTA imersos em gelo e foram imediatamente enviadas para análise.

Foram determinados os valores de hematócrito, hemoglobina, eritrócitos, volume corpuscular médio, hemoglobina corpuscular média, concentração de hemoglobina corpuscular média e plaquetas. O hematócrito foi determinado pela técnica de centrifugação do microhematócrito e a hemoglobina, por espectrofotometria pelo método de cianometahemoglobina.

Os dados foram submetidos ao teste de Shapiro-Wilk para verificação de normalidade. Como não apresentaram distribuição normal, os dados de concentração de hemoglobina corpuscular média foram submetidos à ANOVA de KruskallWallis $(\mathrm{P}<0,05)$. As demais variáveis foram submetidas à análise de variância de duas vias (twoway ANOVA), sendo que as diferenças entre os sexos foram comparadas pelo teste " $\mathrm{t}$ " de Student e o efeito do nível protéico avaliado por regressão polinomial $(\mathrm{P}<0,05)$. Realizaram-se também estudos de correlação de Pearson (r) entre as variáveis observadas. O pacote estatístico "SAS" (1997) foi utilizado para as análises estatísticas.

\section{RESULTADOS E DISCUSSÃO}

Os valores de qualidade da água verificados no experimento foram: temperatura $20,07 \pm 2,52^{\circ} \mathrm{C}$; pH $6,95 \pm 0,15$; oxigênio dissolvido $5,9 \pm 0,78$ ppm; amônia total $1,25 \pm 0,8 \mathrm{ppm}$; nitrito $0,02 \pm 0,003$ ppm; alcalinidade total $45,5 \pm 11,45 \mathrm{mg} \mathrm{CaCO}_{3} / \mathrm{L}$; dureza 54,67 $\pm 11,57 \mathrm{mg} \mathrm{CaCO}_{3} / \mathrm{L}$. Esses valores estão em uma faixa aceitável para o crescimento da espécie (GOMES et al., 2000).

Observou-se que os machos de jundiá apresentaram maiores valores (Tabela 2) de eritrócitos, hematócrito (HT) e hemoglobina (HB) em relação às fêmeas $(\mathrm{P}<0,01)$. Machos de cachara (Pseudoplatystoma fasciatum) capturados de cativeiro apresentaram, da mesma forma que no presente estudo, maiores valores de hematócrito, hemoglobina e eritrócitos (RANZANI-PAIVA et al., 
2005). Isto pode estar associado a hormônios relacionados à reprodução, como a testosterona. Da mesma forma, um aumento do número de eritrócitos influencia também a síntese de hemoglobina.

O nível protéico da dieta e as interações com o sexo não afetaram os valores hematológicos (Tabela 2). Jundiás alimentados com três níveis protéicos $(30,40$ e $50 \% \mathrm{~PB})$ apresentaram aumento linear nos valores de eritrócitos, hematócrito e hemoglobina de acordo com o nível protéico da dieta (CAMARGO et al., 2005), diferentemente do obtido no presente trabalho. Segundo os autores acima citados, a proteína estimula a eritropoiese, aumentando os teores de hemoglobina e mantendo a saúde dos peixes. Deve-se ressaltar também que o peso dos peixes utilizados no presente trabalho é superior aos encontrados em outros estudos. Além disso, a espécie, a idade, o sexo, a qualidade da água e os métodos de captura influenciam na variabilidade dos parâmetros hematológicos em peixes (CAMARGO et al., 2006).

Pela hematologia é possível avaliar o estado de saúde dos peixes frente a diversas alterações no processo de cultivo. Para machos de jundiá, BORGES et al. (2004) salientam que os valores normais de hematócrito e hemoglobina são, respectivamente, $43 \%$ e $8,7 \mathrm{~g} / \mathrm{dL}$. Jundiás com peso inicial de $137 \mathrm{~g}$ e alimentados com dietas contendo $36 \%$ de proteína bruta apresentaram valores de $35 \%$ e $11 \mathrm{~g} / \mathrm{dL}$ para hematócrito e hemoglobina, respectivamente. Juvenis dessa espécie alimentados com dieta contendo $41 \mathrm{ppb}$ de aflatoxinas $/ \mathrm{kg}$ apresentaram valores de hematócrito e hemoglobina de $13,16 \%$ e $8,2 \mathrm{~g} / \mathrm{dL}$, respectivamente (VIEIRA et al., 2006). Esses valores são muito inferiores aos obtidos no presente estudo e em outros trabalhos com o jundiá, caracterizando uma condição de anemia dos peixes.

Outro fator que pode alterar a hematologia do jundiá é a presença de poluentes na água de criação. Diferentes dosagens do herbicida clomazone não alteram os valores de hemoglobina da espécie, entretanto, o tempo de exposição implica na diminuição dos valores de hematócrito (CRESTANI et al., 2006). Deve-se ressaltar que muitas das alterações hematológicas observadas nesses casos dependem muito do tempo de exposição do peixe a um determinado produto.
TABELA 2. Valores de eritrócitos, hemoglobina e hematócrito em jundiás alimentados com dietas contendo diferentes níveis protéicos e separados por sexo

\begin{tabular}{cccc}
\hline & $\begin{array}{c}\text { Eritrócitos } \\
\left(10^{6} / \mathrm{mm}^{3}\right)\end{array}$ & $\begin{array}{c}\text { Hemoglobina } \\
(\mathrm{g} / \mathrm{dL})\end{array}$ & $\begin{array}{c}\text { Hematócrito } \\
(\%)\end{array}$ \\
\hline PB (\%) & & & \\
\hline 24 & 2,43 & 12,25 & 40,13 \\
27 & 2,49 & 12,05 & 38,58 \\
30 & 2,36 & 11,31 & 38,09 \\
Média & 2,43 & 11,87 & 38,93 \\
\hline Sexo & & & \\
\hline Macho & $2,60^{\mathrm{a}}$ & $12,41^{\mathrm{a}}$ & $41,38^{\mathrm{a}}$ \\
Fêmea & $2,22^{\mathrm{b}}$ & $11,05^{\mathrm{b}}$ & $36,05^{\mathrm{b}}$ \\
Média & 2,41 & 11,73 & 38,72 \\
\hline ANOVA & & & \\
\hline PB & NS & NS & NS \\
Sexo & $* *$ & $* *$ & $* *$ \\
PB x Sexo & NS & NS & NS \\
CV (\%) & 9,13 & 8,37 & 8,85 \\
\hline
\end{tabular}

Médias com letras diferentes, na coluna, apresentam diferença significativa pelo teste " $t$ " $(\mathrm{P}<0,01)$.

$* * \mathrm{P}<0,01 . \mathrm{NS}=$ não significativo $(\mathrm{P}>0,05)$.

Os valores de hematócrito (34-40\%) observados por GREENE \& SELIVONCHIK (1990) em trutas alimentadas com diferentes fontes de lipídios são similares aos observados para os jundiás no presente trabalho. Os autores salientam que alterações nutricionais influenciam os parâmetros hematológicos e também que os valores observados para cada espécie de peixe devem estar dentro de uma faixa considerada "normal". Abaixo ou acima dessa faixa, o animal estará possivelmente em uma condição de saúde inadequada.

Corroborando com os resultados obtidos neste trabalho, juvenis de jundiá (70-100g) alimentados com quatro níveis de proteína na dieta $(20,27,34$ e 41\%PB) também não apresentaram variações nos parâmetros sanguíneos (MELO et al., 2006).

Foram observadas correlações significativas entre hemoglobina e hematócrito $(0,94, \mathrm{P}<0,0001) \mathrm{e}$ entre hematócrito e eritrócitos $(0,83, \mathrm{P}<0,0001)$. Para o cachara, RANZANI-PAIVA et al. (2005) observaram altas correlações $(0,84$ e 0,76$)$ para as 
mesmas variáveis, respectivamente. Para trutas alimentadas com diferentes fontes de lipídios, observou-se alta correlação entre hematócrito e hemoglobina (GREENE \& SELIVONCHICK, 1990).

Os valores de volume corpuscular médio (VCM) e de hemoglobina corpuscular média (HCM) não apresentaram diferenças entre sexos e não sofreram influência do nível protéico da dieta (Tabela 3). Os peixes alimentados com a dieta contendo $27 \%$ de proteína bruta apresentaram maior valor de concentração de hemoglobina corpuscular média. Os valores de VCM verificados no presente estudo (154-165 fL) foram superiores aos encontrados para jundiás alimentados com dieta contendo $34 \%$ PB e criados em tanque de terra (139 fL) (TAVARES-DIAS et al., 2002). Por outro lado, os valores de concentração de hemoglobina corpuscular média foram similares.

A quantidade de plaquetas foi maior nas fêmeas $(\mathrm{P}<0,01)$ e também nos peixes alimentados com o maior valor de proteína dietária testada $(30 \%$ PB). Para o jundiá, informações sobre o efeito da nutrição nas plaquetas são inexistentes. As informações existentes para a espécie referem-se mais às células de defesa como linfócitos, monócitos, trombócitos e eosinófilos.

As variações dos valores dos parâmetros hematológicos em peixes são grandes porque existem inúmeras causas, o que dificulta a comparação de resultados mesmo em trabalhos com a mesma espécie. O trabalho de TAVARES-DIAS \& SANDRIN (1998) demonstra que os valores de hematócrito e hemoglobina do sangue heparinizado são superiores se comparados ao colhido com EDTA, em um mesmo peixe.

Para o jundiá e outras espécies nativas brasileiras, é importante que mais estudos sobre hematologia em diferentes condições nutricionais sejam conduzidos. Isto porque, geralmente, enfatizase exclusivamente o aspecto de ganho em peso, sem levar em consideração o estado metabólico e de saúde dos peixes. Além disso, muitos mercados preconizam a criação dos peixes em condição de bem-estar, sendo a hematologia uma ferramenta importante para monitorar tal condição. Os valores observados neste estudo refletem apenas uma condição específica de manejo com o jundiá.
TABELA 3. Valores de volume corpuscular médio (VCM), hemoglobina corpuscular média (HCM), plaquetas (PLT) e concentração de hemoglobina corpuscular média (CHCM) em jundiás alimentados com dietas contendo diferentes níveis protéicos e separados por sexo

\begin{tabular}{ccccc}
\hline & $\begin{array}{c}\text { VCM } \\
(\mathrm{fL})\end{array}$ & $\begin{array}{c}\text { HCM } \\
(\mathrm{pg})\end{array}$ & PLT & $\begin{array}{c}\text { CHCM } \\
(\mathrm{g} / \mathrm{dL})\end{array}$ \\
\hline PB (\%) & & & & \\
\hline 24 & 165,3 & 50,48 & 66500 & 30,53 \\
27 & 154,73 & 48,48 & 52000 & $31,35^{*}$ \\
30 & 162,04 & 48,16 & 87125 & 29,73 \\
Média & 160,69 & 49,04 & 68541,7 & 30,54 \\
\hline Sexo & & & & \\
\hline Macho & 159,9 & 47,9 & $64000^{\mathrm{b}}$ & 29,96 \\
Fêmea & 162,15 & 49,74 & $82375^{\mathrm{a}}$ & 30,7 \\
Média & 161,03 & 48,82 & 73187,5 & 30,33 \\
\hline ANOVA & & & & \\
\hline PB & NS & NS & $* *$ & $*$ \\
Sexo & NS & NS & $* *$ & NS \\
PB x Sexo & NS & NS & NS & NS \\
CV (\%) & 7,08 & 6,72 & 17,09 & 3,41 \\
\hline
\end{tabular}

Médias com letras diferentes, na coluna, apresentam diferença significativa pelo teste "t" $(\mathrm{P}<0,01)$.

${ }^{*} \mathrm{P}<0,05 ; * * \mathrm{P}<0,01 . \mathrm{NS}=$ não significativo $(\mathrm{P}>0,05)$.

\section{CONCLUSÃO}

Conclui-se que machos de jundiá apresentam parâmetros hematológicos superiores às fêmeas. A proteína dietária influencia na quantidade de plaquetas e na concentração de hemoglobina corpuscular dos jundiás.

\section{AGRADECIMENTOS}

Os autores expressam agradecimento à SEAP/MCT/FINEP/Fundo Setorial Agronegócio/Fundo CT Hidro-Aquicultura (processo n.3602/05) pelo auxílio financeiro ao trabalho, à CAPES pelo fornecimento de bolsa de estudos para Rafael Lazzari e ao CNPq pela bolsa de produtividade em pesquisa (1D) para o professor João Radünz Neto. Também à FAPERGS pela bolsa de iniciação científica para Viviani Corrêia. Ao Laboratório de Análises Médicas (LABIMED, Santa Maria - RS) pela realização das análises. 


\section{REFERÊNCIAS}

APHA (American Public Health Association). Standard Methods for the Examination of Water and Wastewater, 21 ${ }^{\mathrm{a}}$ ed., Eaton, A.D. et al. (Editores), Washington, DC, 1368p., 2005.

AWWA (American Water Works Association). Processos simplificados para exame e análise da água. São Paulo, 276p., 1970.

BARCELLOS, J.L.G.; KREUTZ, L.C.; QUEVEDO, R.M.; FIOREZE, I.; CERICATO, L. ; SOSO, A.B.; FAGUNDES, M.; CONRAD, J.; BALDISSERA, R.K.; BRUSCHI, A; RITTER, F. Nursery rearing of jundiá, Rhamdia quelen (Quoy \& Gaimard) in cages: cage type, stocking density and stress response to confinement. Aquaculture, v. 232, p.383-394, 2004.

BORGES, A., SCOTTI, L.V., SIQUEIRA, D.R., JURINITZ, D.F., WASSERMANN, G.F. Hematologic and serum biochemical values for jundiá (Rhamdia quelen). Fish Physiology and Biochemistry, v.30, p.2125, 2004.

CAMARGO, S.O., POUEY, J.L., MARTINS, C. Parâmetros eritrocitários do jundiá (Rhamdia quelen) submetido à dieta com diferentes níveis de proteína. Ciência Rural, v.35, n.6, p.1406-1411, 2005.

CAMARGO, S.O.; POUEY, J.L.; VAZ, B.S. Efeito da salinidade nos parâmetros hematológicos do jundiá (Rhamdia quelen - Quoy \& Gaimard, 1824). Revista Brasileira de Agrociência, v.12, n.4, p.453-460, 2006.

CRESTANI, M., MENEZES, C., GLUSCZAK, L., MIRON, D., LAZZARI, R., DUARTE, M.F., MORSCH, V.M., PIPPI, A.L., VIEIRA, V.P. Effects of clomazone herbicide on hematological and some parameters of protein and carbohydrate metabolism of silver catfish Rhamdia quelen. Ecotoxicology and Environmental Safety, v.65, p.48-55, 2006.

FRIES, J. Análisis de trazas: métodos fotométricos comprobados. Darmstadt, Ed. Merck, 184p., 1971.

GOMES, L.C.; GOLOMBIESKI, J.I.; CHIPPARI GOMES, A.R.; BALDISSEROTTO, B. Biologia do Jundiá Rhamdia quelen (Teleostei, Pimelodidae). Ciência Rural, v.30, n.1, p.179-185, 2000.

GREENE, D.H.S.; SELIVONCHICK, D.P. Effects of dietary vegetable, animal and marine lipids on muscle lipid and hematology of rainbow trout (Oncorhynchus mykiss). Aquaculture, v.89, p.165-182, 1990.
KLINGER, R.C.; BLAZER, V.S.; ECHEVARRIA, C. Effects of dietary lipid on the hematology of channel catfish, Ictalurus punctatus. Aquaculture, v.147, p.225233, 1996.

LAZZARI, R., RADÜNZ NETO, J., EMANUELLI, T., PEDRON, F.A., COSTA, M.L., LOSEKANN, M.E., CORREIA, V., BOCHI, V.C. Diferentes fontes protéicas para a alimentação do jundiá (Rhamdia quelen). Ciência Rural, v.36, n.1, p.240-246, 2006.

MELO, J.F.B.; TAVARES-DIAS, M.; LUNDSTEDT, L.M. ; MORAES, G. Efeito do conteúdo de proteína na dieta sobre os parâmetros hematológicos e metabólicos do bagre sul americano Rhamdia quelen. Revista Ciência Agroambiental, v.1, n.1, p.43-51, 2006.

MEYER, G., FRACALOSSI, D.M. Protein requirement of jundiá fingerlings, Rhamdia quelen, at two dietary energy concentrations. Aquaculture, v.240, p.331-343, 2004.

PIEDRAS, S.R.N., POUEY, J.L.O.F., MORAES, P.R.R. Resposta de alevinos de jundiá (Rhamdia sp.) alimentados com diferentes níveis de proteína bruta e energia digestível. Revista Brasileira de Agrociência, v.12, n.2, p.207-220, 2006.

RANZANI-PAIVA, M.J., ROMAGOSA, E., ISHIKAWA, C.M. Hematological parameters of "Cachara", Pseudoplatystoma fasciatum Linnaeus, 1766 (Osteichthyes, Pimelodidae), reared in captivity. Boletim do Instituto de Pesca, v.37, n.1, p.47-53, 2005.

ROMANI, R., ANTOGNELLI, C., BALDRACCHINI, F., DE SANTIS, A., ISANI, G., GIOVANNINI, E., ROSI, G. Increased acetylcholinesterase activities in specimens of Sparus auratus exposed to sublethal copper concentrations. Chemico-Biological Interactions, v.145, p.321-329, 2003.

SALHI, M., BESSONART, M., CHEDIAK, G., BELLAGAMBA, M., CARNEVIA, D. Growth, feed utilization and body composition of black catfish, Rhamdia quelen, fry fed diets containing different protein and energy levels. Aquaculture, v.231, p.435444, 2004.

SAS INSTITUTE. Statistical Analysis System. User's Guide. Version 6.08, SAS INSTITUTE INC. 4.Ed. North Caroline. <SAS INSTITUTE INC>, 846 p., 1997.

TAVARES-DIAS, M.; MELO, J.F.B.; MORAES, G.; MORAES, F.R.. Características hematológicas de teleósteos brasileiros IV - Variáveis do jundiá Rhamdia quelen (Pimelodidae). Ciência Rural, v.32, n.4, p. 693698, 2002.

Protocolado em: 26 jan. 2008. Aceito em: 29 mar. 2011. 